\title{
Assessment of the Adsorption Kinetics and Equilibrium for the Potential Removal of Direct Yellow - 12 Dye Using Jatropha Curcus L. Activated Carbon
}

\author{
G.REVATHI $^{1}$, S.RAMALINGAM ${ }^{2 *}$ and P.SUBRAMANIAM ${ }^{3}$ \\ ${ }^{1}$ Department of Chemistry, Sri Subramanya College of Engineering and Technology, \\ Palani- 624 615, India \\ ${ }^{2}$ Department of Chemistry, Vivekananda College, \\ Agasteeswaram- 629 701, India \\ ${ }^{3}$ Department of Chemistry, Aditanar College of Arts and Science, \\ Tiruchendur-628216, India \\ revathi_udt@yahoo.com
}

Received 28 April 2013 / Accepted 7 June 2013

\begin{abstract}
Removal of DY-12 dye from aqueous solutions at different concentrations, $\mathrm{pH}$ and effect of contact time by Jatropha Curcus L. (family: Euphorbiaceae) tree leaves activated carbon (JCTC) has been carried out successfully. The percentage of the dye adsorbed was found to be $87.05 \%$ for $1 \mathrm{~g}$ of the carbon. Batch adsorption experiments were carried out successfully. The initial $\mathrm{pH}$ of the dye solutions was maintained at 7.8. The removal of the dye DY -12 by JCTC increased from 22.65 to $39.31 \mathrm{mgg}^{-1}$ by increasing the concentration of the dye from 30 to $60 \mathrm{ppm}$ at temperature $27 \pm 1{ }^{\circ} \mathrm{C}$ and $\mathrm{pH} \mathrm{7.8}$. However, the percentage of the dye adsorbed is decreases from 75.50 to $65.52 \%$, by increasing the concentration of the dye from 30 to $60 \mathrm{ppm}$. The time required to attain equilibrium in the case of adsorption of dyes is $20 \mathrm{~min}$. It can be seen from the figure that the equilibrium period remains unaltered with the change of initial concentration of the dye solution. The value of $R_{L}$ for the adsorption is nearly 1 , indicates that the adsorption process is very favourable. The equilibrium sorption capacity of the dye is 0.361 . Volume that could be treated is found to be $261.89 \mathrm{~L} / \mathrm{g}$. From column experiments effect of bed depth, contact time analyses were studied. It is found that these plots are linear in nature and obey the linear relationship $S=a+b c$. The reaction follows a first order kinetics. Rate of adsorption depend on the concentration of dye solution. The data fits into the first order kinetic models of Langmuir, Freundlich, Intra-particle diffusion, Bhattacharya-Venkobhachar equation, Lagergren's equation, Natarajan Khalaf equation and also obeys Elovich equation, Modified Elovich equation and pseudo second order kinetic equations excellently. The SEM analysis and FT-IR spectrum clearly shows that the adsorption is by the physical forces and not by the chemical combinations.
\end{abstract}

Keywords: Adsorption, JCTC, DY-12 dye, $\mathrm{R}_{\mathrm{L}}$ factor, Sorption capacity 


\section{Introduction}

Water pollution is one of the most undesirable environmental problems in the world and it requires solutions. Textile industries produce a lot of wastewater, which contains a number of contaminants, including acidic or caustic dissolved solids, toxic compounds and many different dyes. Many of the organic dyes are hazardous and may affect aquatic life causing various diseases and disorders ${ }^{1}$. Due to their chemical structures, dyes are resistant to fading on exposure to light, water and many chemicals and therefore, are different to be decolourized once released into the aquatic environment ${ }^{2}$.

Various techniques have been employed for dye removal from wastewater. Currently, the principal methods of treatment involve biological, physical and/or chemical processes ${ }^{2-10}$. In the present study, activated carbon prepared from tree leaves was used as an adsorbent for the removal of Direct Yellow (DY-12) dye (Figure 1). The materials chosen are available in large quantities as bio-waste and at low cost. The aim of the present work is to explore the possibility of using these carbonaceous materials as low-cost adsorbent.

\section{Experimental}

The dye adsorbate and preparation of the adsorbent and the adsorbate (DY-12) (Microscopic grade, Sigma-Aldrich, India) were used without further purification. All solutions were made in double distilled water. Mature Kattamanakku leaves (Jatropha curcus L), collected from a number of trees, were mixed together and washed repeatedly with water to remove dust and other impurities. The leaves were dried first at room temperature in a shade and then washed with distilled water and soaked in $98 \%$ sulphuric acid $(1: 2 \mathrm{w} / \mathrm{v})$ and heated separately for $24 \mathrm{~h}$ at $100{ }^{\circ} \mathrm{C}$ in a muffle furnace. After treatment the samples were cooled to room temperature and washed with distilled water until the filtrates attained neutral $\mathrm{pH}$. The resulting activated carbon materials (JCTC) were dried in a hot air oven at 333-343 $\mathrm{K}$ for $30 \mathrm{~h}$ till they could be crushed into fine powder. The powdered carbon was sieved and the 53-74 micro fractions were preserved as an adsorbent in glass bottles.

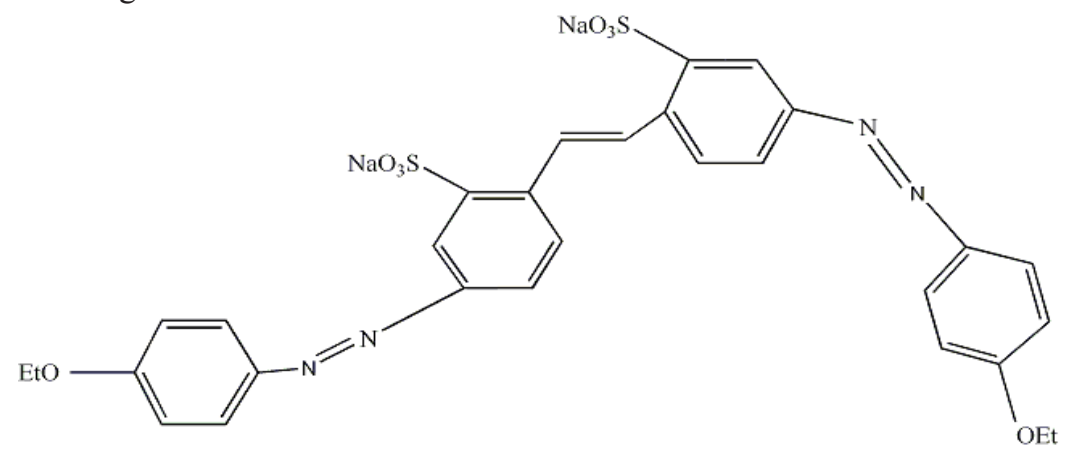

Figure 1. Chemical Structure of DY-12

\section{Adsorbates}

The dye in the present study was selected from the list of dyes normally used in India, e.g. methylene blue, malachite green, direct yellow-12, crystal violet, rhodamine B, and Grey BL in paper industry, synthetic fibre and textiles industries. Synthetic wastewater was prepared by dissolving DY-12 dye. The chemical nature of the adsorbate has profound effect on the adsorption characteristics. 


\section{Results and Discussion}

\section{Characteristics of carbon system}

\section{Effect of carbon dose and $\mathrm{pH}$}

To find out the minimum amount of carbon required for maximum percentage of DY-12 dye adsorption, $100 \mathrm{~mL}$ of $100 \mathrm{ppm}$ dye solution was taken in different stoppered reagent glass bottles and varied quantities of carbon ( 0.1 to $1.4 \mathrm{~g})$ were added and equilibrated using rotatory mechanical shaker for five hours. The percentage of dye removal was calculated from the absorbance. The results are presented in Table 1 and the corresponding plot of carbon dose against percentage of dye removal is presented in Figure 2.

Table 1. Effect of carbon dose

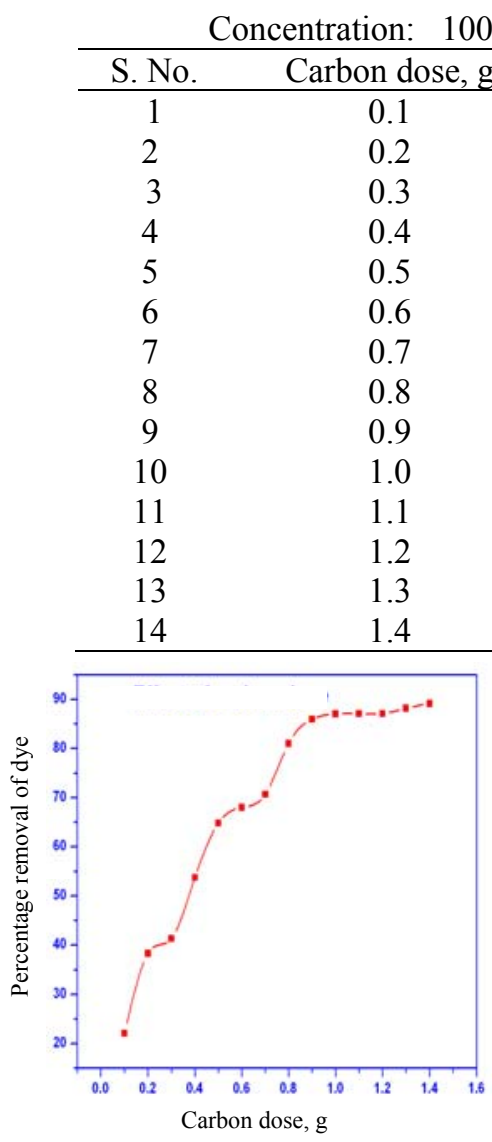

Figure 2. Effect of carbon dose

\begin{tabular}{c} 
Spm $\quad 70$ micron \\
Percentage removal of dye \\
\hline 22.11 \\
38.35 \\
41.34 \\
53.70 \\
64.82 \\
68.06 \\
70.69 \\
81.05 \\
85.98 \\
87.05 \\
87.09 \\
87.11 \\
88.18 \\
89.19
\end{tabular}

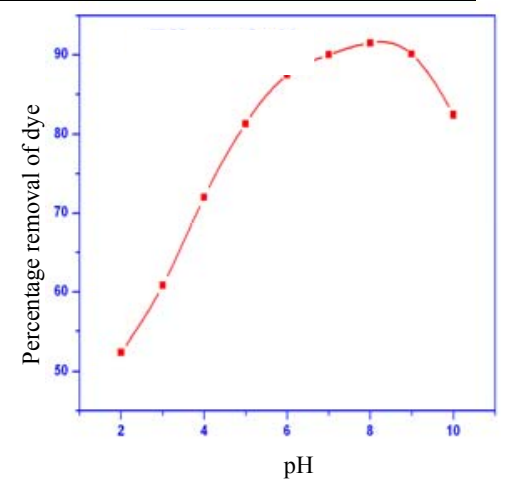

Figure 3. Effect of $\mathrm{pH}$

The percentages of dye sorbed increase as the sorbent dose was increase over the range 0.1 to $1.4 \mathrm{~g}$ and it is found to be the adsorption equilibrium of dye was reached at $1 \mathrm{~g}$ of sorbent. The $\mathrm{pH}$ of carbon indicates that is very nearer to neutral (Figure 3).

SEM analysis

The SEM images of activated carbon (KTC) and dye adsorbed carbon reveal the surface textures and porosity of the samples. 
The pore size of cavity in the carbon sample is clearly detectable (Figure 4) and is roughly of the order of 100-120 $\mu \mathrm{m}$. The presence of dye particles on the surface of activated carbon (Figure 5) as noted by the bright spots ${ }^{11}$ indicates that the adsorption of dyes on the activated carbon is a surface phenomenon.

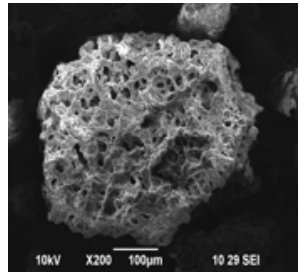

Figure 4. SEM image of carbon

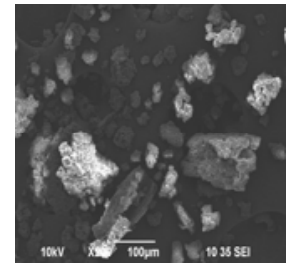

Figure 5. SEM image of dye loaded carbon

\section{FT-IR spectral studies}

FT-IR spectra of the activated carbon, before and after adsorption of the dye have been recorded. The representative spectrum is shown below (Figure 6). From the spectra it could be seen that the peak position is not changed indicate that the adsorption of dye on the activated carbon is by the physical forces and not by the chemical combinations ${ }^{12}$.

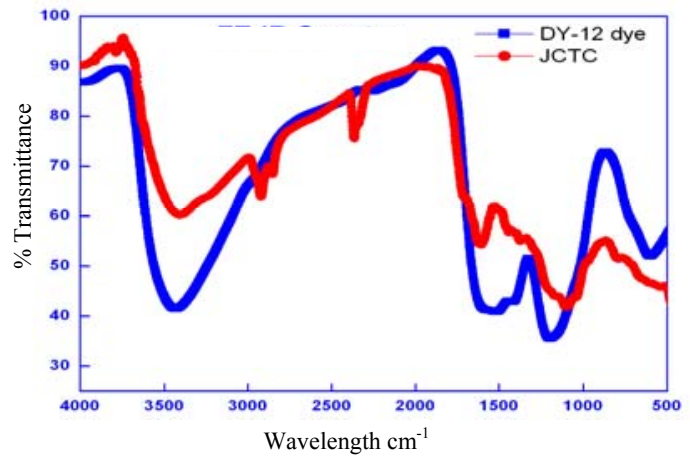

Figure 6. FT-IR spectra

\section{Characteristics of carbon systems}

The solubility of carbon in acid is higher than that of their solubility in water. The surface areas of activated carbons are found to be higher in nature and it can be used as better adsorbent to remove the dyes.

Table 2. Characteristics of carbon system

\begin{tabular}{cll}
\hline S. No. & \multicolumn{1}{c}{ Description } \\
\hline 1 & Moisture content \% & 24.90 \\
2 & Ash content \% & 0.266 \\
3 & Bulk density $\mathrm{g} / \mathrm{mL}$ & 0.2527 \\
4 & $\mathrm{pH}$ & 7.8 \\
5 & Carbon solubility in water \% & 1.0546 \\
6 & Carbon solubility in acid \% & 1.5553 \\
7 & Decolourising power $\mathrm{mg} / \mathrm{g}$ & 73.5 \\
8 & Ion exchange capacity m equi $/ \mathrm{g}$ & 0.4866 \\
9 & Phenol number ppm & 375.0 \\
10 & Surface Area $\mathrm{m}^{2} / \mathrm{g}$ & 467.38 \\
\hline
\end{tabular}




\section{Effect of equilibration period}

In a series of reagent bottles, $100 \mathrm{~mL}$ of $100 \mathrm{ppm}$ direct yellow-12 dye solution was taken and $10 \mathrm{~mL} \mathrm{pH}$ of 7.5 is added. To this a carbon dose of $1.0 \mathrm{~g}$ of carbon powder is added. These bottles are agitated in a mechanical shaker and at different time intervals bottles are removed from the shaker and kept for settlement. Then the filtrate is subjected to absorbance measurements. The percentage of dye removal is given in Table 3 and is graphically represented in Figure 7.

Table 3. Effect of equilibration period

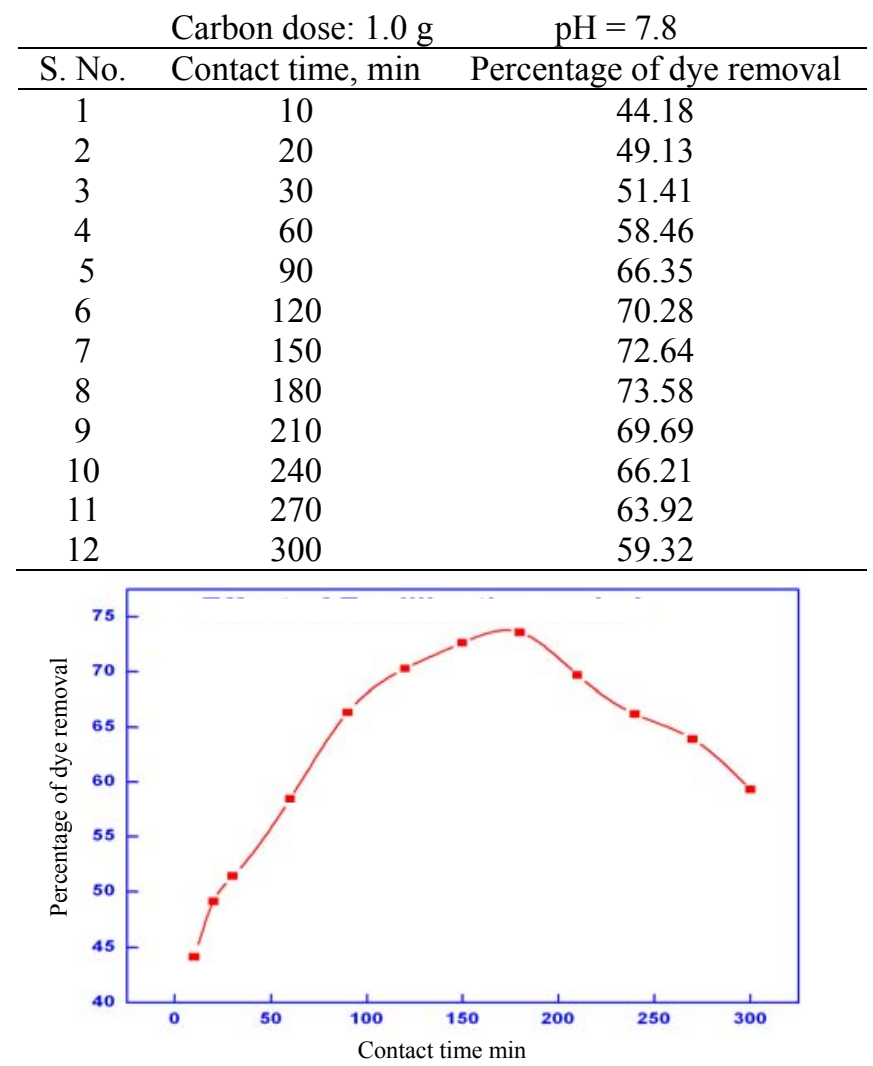

Figure 7. Effect of equilibration period

The rate of percent removal of dye was increased and attains equilibrium at 210 minutes and then gradually decreases. The initial faster rate may be due to the availability of the uncovered surface area of the adsorbent, since adsorption kinetics depends on the surface area of the adsorbent.

\section{Desorption studies by acid method}

Desorption process results in getting fresh carbon systems, which can be reused. The strong acids like $\mathrm{HCl}$ and $\mathrm{H}_{2} \mathrm{SO}_{4}$ are used by Huang et al., ${ }^{13}$ for desorption process. The reversibility of adsorbed dye in mineral acid is in agreement with the $\mathrm{pH}$ dependent results (Figure 8) obtained. Desorption of dye by mineral acids $\left(\mathrm{HCl} \& \mathrm{H}_{2} \mathrm{SO}_{4}\right)$ indicates that the dye was adsorbed onto the activated carbon through physisorption mechanism. 


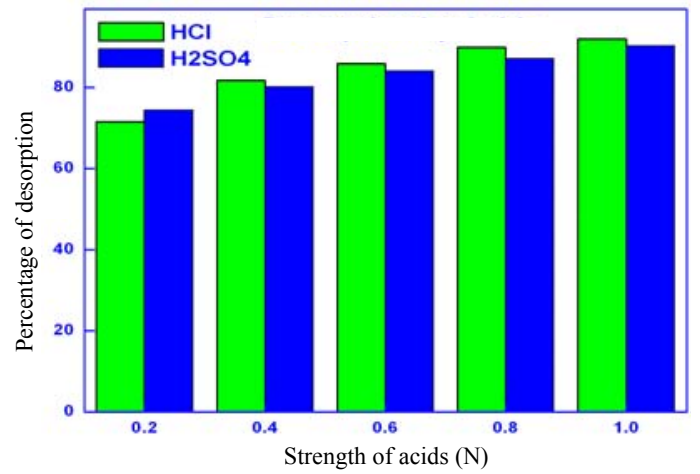

Figure 8. Desorption by Acids

\section{Effect of contact time and concentration}

The adsorbate concentration and contact time between adsorbent and adsorbate species play a significant role in the process of removal of pollutants from water and wastewater by adsorption at a particular temperature and $\mathrm{pH}$. A rapid uptake of pollutants (dye) and establishment of equilibrium in a short period signifies the efficiency of the adsorbent for its use in wastewater treatment. In addition to this, the contact time is one of the factors for the development of surface charges at the solid solution interface. The initial concentration of adsorbate also plays an important role as a given mass of the adsorbent can adsorb only a fixed amount of the solute.

The finding of the present investigation is given in Table 4 . The removal of the dye DY12 by JCTC increased from 22.65 to $39.31 \mathrm{mgg}^{-1}$ by increasing the concentration of the dye from 36 to $60 \mathrm{ppm}$ at temperature $27 \pm 1^{\circ} \mathrm{C}$ and $\mathrm{pH} 7.8$. However, the percentage of the dye adsorbed is decreases from 75.50 to $65.52 \%$ for DY-12 by increasing the concentration of the dye from 30 to $60 \mathrm{ppm}$.

Table 4. Amount percentage and equilibrium time of DY-12 dye adsorbed ( $\mathrm{pH} 7.8$; Temperature $27^{\circ} \mathrm{C}$ )

\begin{tabular}{cccc}
\hline Conc. of DY-12, ppm & Amount adsorbed, mg/g & \% Removal & Equilibrium time, min \\
\hline 30 & 22.65 & 75.50 & 20 \\
40 & 27.61 & 69.02 & 20 \\
50 & 33.52 & 67.04 & 20 \\
60 & 39.31 & 65.52 & 20 \\
\hline
\end{tabular}

\section{Adsorption experiments}

Batch adsorption experiments were carried out by shaking the adsorbent with an aqueous solution of the dye of desired concentration in corning glass bottles at $27 \pm 1{ }^{\circ} \mathrm{C}$ in a water thermostat. The initial $\mathrm{pH}$ of the dye solutions was maintained at 7.8. Absorbance was determined using ELICO BL 222 double beam UV-Vis bio-spectrophotometer. Calibration curves are obtained with standard (DY-12) $\left(\lambda_{\max }=420\right)$ dye solutions and the amounts adsorbed were found by mass-balance procedure.

\section{Kinetics of adsorption}

The kinetics of the adsorption processes was studied by carrying out a separate set of experiments with constant temperature, JCTC amount and adsorbate concentration using the pseudo first orders Lagergren equation ${ }^{14}$. The differential rate equation is of the form: 


$$
\mathrm{d}_{\mathrm{q}} / \mathrm{d}_{\mathrm{t}}=\mathrm{k}_{1}\left(\mathrm{q}_{\mathrm{e}}-\mathrm{q}_{\mathrm{t}}\right)
$$

Where $\mathrm{q}_{\mathrm{e}}$ and $\mathrm{q}_{\mathrm{t}}$ are the amount adsorbed per unit mass of the adsorbent (in $\mathrm{mg} \mathrm{g}^{-1}$ ) at equilibrium and at time $t$ and $k_{1}$ is the pseudo first order rate constant $\left(\mathrm{min}^{-1}\right)$. Integrating the above equation for the boundary conditions $\mathrm{t}=0$ to $\mathrm{t}=\mathrm{t}$ and $\mathrm{q}_{\mathrm{t}}=0$ at $\mathrm{t}=0$, gives:

$$
\log \left(\mathrm{q}_{\mathrm{e}}-\mathrm{q}_{\mathrm{t}}\right)=\log \mathrm{q}_{\mathrm{e}}-\mathrm{k}_{1} \mathrm{t} /(2: 303)
$$

A linear plot of $\log \left(\mathrm{q}_{\mathrm{e}}-\mathrm{q}_{\mathrm{t}}\right)$ vs. $\mathrm{t}$ verifies the first order kinetics with the slope yielding the value of the rate constant.

\section{Intra-particle diffusion}

The variation in the extent of adsorption with time at different initial dye concentrations was processed for evaluating the role of diffusion in the adsorption system. Adsorption is a multi-step process involving transport of the solute molecules from the aqueous phase to the surface of the solid particulates followed by diffusion into the interior of the pores. The intra-particle diffusion rate equation ${ }^{15-16}$ :

$$
\mathrm{q}_{\mathrm{t}}=\mathrm{k}_{\mathrm{i}} \mathrm{t}_{0.5}
$$

Where $\mathrm{k}_{\mathrm{i}}$ is the intra-particle diffusion rate constant $\left(\mathrm{mg} \mathrm{g}^{-1} \min ^{-0.5}\right)$. The $\mathrm{k}_{\mathrm{i}}$ values were calculated from the slopes of the linear plots of $\mathrm{q}_{\mathrm{t}} v \mathrm{~s} . \mathrm{t}^{0.5}$.

\section{Adsorption isotherms}

The well-known Freundlich isotherm, Equation (3), is widely used to describe adsorption on a surface having heterogeneous energy distribution. The Langmuir isotherm, Equation (4) on the other hand is strictly applicable to monolayer chemisorption. The experimental data are tested with respect to both these isotherms:

Freundlich isotherm:

Langmuir isotherm:

$$
\mathrm{q}_{\mathrm{e}}=\mathrm{K}_{\mathrm{f}} \mathrm{Cn}
$$

$$
\mathrm{C}_{\mathrm{e}} / \mathrm{q}_{\mathrm{e}}=\left(1 / \mathrm{K}_{\mathrm{d}} \mathrm{C}_{1}\right)+\left(1 / \mathrm{C}_{1}\right) \mathrm{Ce}
$$

Where $\mathrm{q}_{\mathrm{e}}$ is the amount of dye adsorbed at equilibrium in unit mass, $\mathrm{C}_{\mathrm{e}}$ is the concentration of the dye in aqueous phase at equilibrium, $\mathrm{n}$ and $\mathrm{K}_{\mathrm{f}}$ are Freundlich coefficients, $\mathrm{C}_{1}$ and $\mathrm{K}_{\mathrm{d}}$ are Langmuir coefficients. The linear Freundlich and Langmuir plots were obtained by plotting (i) $\log \mathrm{q}_{\mathrm{e}} v s . \log \mathrm{C}_{\mathrm{e}}$ and (ii) $\mathrm{C}_{\mathrm{e}} / \mathrm{q}_{\mathrm{e}}$ vs. $\mathrm{C}_{\mathrm{e}}$, and the adsorption coefficients were computed from the slopes and the intercepts. Another important parameter, $\mathrm{R}_{\mathrm{L}}$, known as the separation factor, could be obtained from the relation:

$$
\mathrm{R}_{\mathrm{L}}=1 /\left(1+\mathrm{K}_{\mathrm{d}} \mathrm{C}_{\mathrm{ref}}\right)
$$

Where $\mathrm{C}_{\text {ref }}$ is any equilibrium liquid phase concentration of the solute. It has been established ${ }^{17} 12$ that (i) $0<\mathrm{R}_{\mathrm{L}}<1$ for favourable adsorption, (ii) $\mathrm{R}_{\mathrm{L}}>1$ for unfavourable adsorption, (iii) $\mathrm{R}_{\mathrm{L}}=1$ for linear adsorption, and (iv) $\mathrm{R}_{\mathrm{L}}=0$ for irreversible adsorption.

It is clear from Figure 9 that the extent of adsorption is rapid in the initial stages and becomes slow in later stages till saturation is attained. This is obvious from the fact that a large number of surface sites are available for adsorption at the initial stages and after a lapse of time, the remaining surface sites are difficult to be occupied because of repulsion between the solute molecules of the solid and bulk phases. The time required to attain equilibrium in the case of adsorption of dyes is $20 \mathrm{~min}$. It can be seen from the figure that the equilibrium period remains unaltered with the change of initial concentration of the dye solution. 


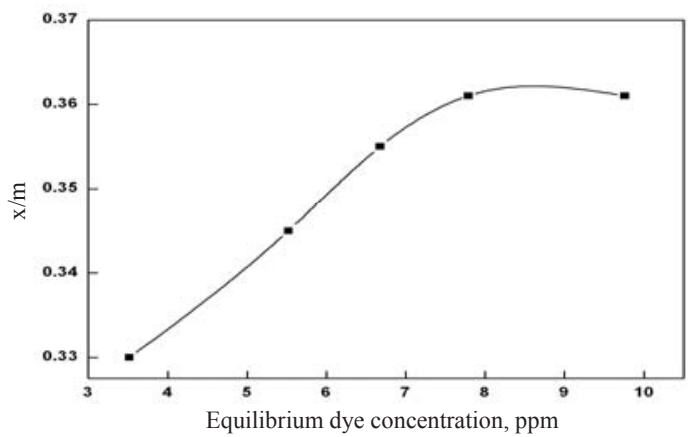

Figure 9. Equilibrium sorption curve

A series of contact experiments were undertaken for varying initial dye concentrations namely 30, 40, 50 and $60 \mathrm{ppm}$. For low concentrations, there was a rapid uptake of dye due to surface mass transfer ${ }^{12}$. The time variation curves for adsorption are simple, smooth and continuous, indicating the formation of monolayer coverage on the surface of adsorbent. The Langmuir isotherm is valid for monolayer adsorption onto a surface containing a finite number of identical sites. The model assumes uniform energies of adsorption onto the surface and no transmigration of adsorbate in the plane of surface. The experimental data for the uptake of the dye by adsorbent (Jatroba Curcus L. leaves powder carbon) have been correlated with the rearranged Langmuir's model of adsorption in the present investigation:

$$
\mathrm{C}_{\mathrm{e}} / \mathrm{q}_{\mathrm{e}}=\left(\mathrm{C}_{\mathrm{e}} / \mathrm{Q}^{0}\right)+\left(1 / \mathrm{Q}^{0} \mathrm{~b}\right)
$$

Where $\mathrm{C}_{\mathrm{e}}$ is the equilibrium concentration $\left(\mathrm{mg} \mathrm{L}^{-1}\right)$ of the dye, $\mathrm{q}_{\mathrm{e}}$ is the amount $\left(\mathrm{mg} \mathrm{g}^{-1}\right)$ of the dye adsorbed at equilibrium and $\mathrm{Q}^{0}$ Fig. 6. Langmuir plot for the adsorption of DY-12 on JCTC at a temperature of $27{ }^{\circ} \mathrm{C}$ and $\mathrm{b}$ are the Langmuir constants related to adsorption capacity and energy of the adsorption, respectively. The plot of $\mathrm{C}_{\mathrm{e}} / \mathrm{q}_{\mathrm{e}}$ versus $\mathrm{C}_{\mathrm{e}}$ at $27^{\circ} \mathrm{C}$ for the DY-12 (Figure 10) is found to be linear, suggesting the applicability of Langmuir isotherm.

The Figure 11 shows the plot of the log values of amount of dye adsorbed per weight of carbon against the log values of equilibrium dye concentration $\left(\mathrm{C}_{\mathrm{e}}\right)$. The straight-line nature of the plot indicates that the process followed were Freundlich type of adsorption. The ' $k$ ' values of Freundlich adsorption equations were obtained for carbon from the intercept of straight line and $\log 1 / \mathrm{n}$ value, i.e., sorption intensities are calculated from the slope.

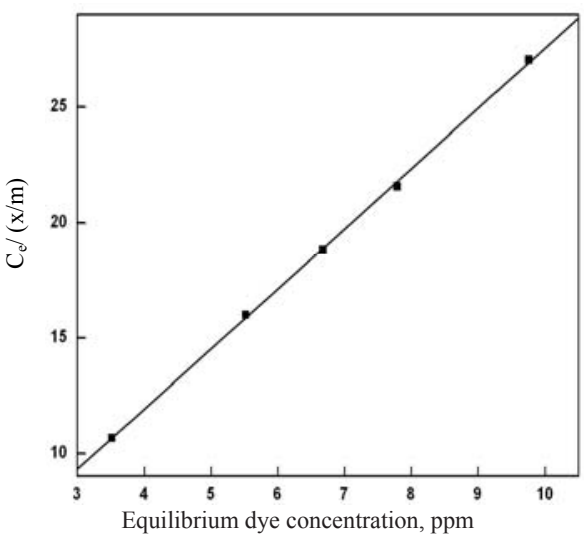

Figure 10. Langumuir plot

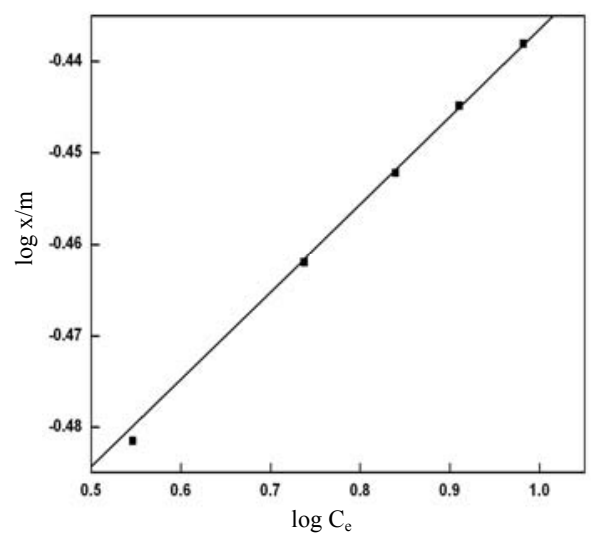

Figure 11. Freundlich plot 
The essential characteristics of a Langmuir isotherm can be described by a separation factor or equilibrium parameters RL which is defined by

$$
R_{L}=\frac{1}{1+b C_{o}}
$$

Where Co is the critical concentration (ppm) and $\mathrm{b}$ is the Langmuir constant. The value of $\mathrm{R}_{\mathrm{L}}$ for the adsorption of DY-12 on JCTC leaves powder indicates that the adsorption process is very favourable because $\mathrm{R}_{\mathrm{L}}$ value lies between 0 and 1 . An equilibrium sorption capacity of the dye was 0.361 .

The adsorption equation can be used to determine the volume of dye solution to be treated to bring down the dye concentration to the permissible levels. The sorption capacity is first calculated by substituting the effluent concentration $0.1 \mathrm{ppm}$ in the above sorption equation. Volume that could be treated in litre is found to be $261.89 / \mathrm{g}$.

\section{Column studies}

From column experiments effect of bed depth, contact time analyses were studied. The relationship between percentage of adsorbed dye and bed depth is derived for the contact range and the representative plots of bed depth $v$ s. percentage of adsorbed dye solutions are presented in Figure $12 \&$ 13. It is found that these plots are linear in nature and obey the linear relationship $\mathrm{S}=\mathrm{a}+\mathrm{bc}$. Where $\mathrm{S}$ is the percentage of dye adsorbed, a and $\mathrm{c}$ are constants.

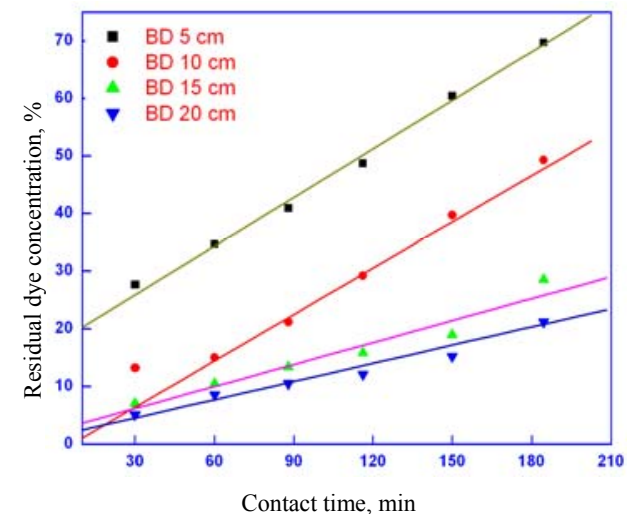

Figure 12. Effect of contact time

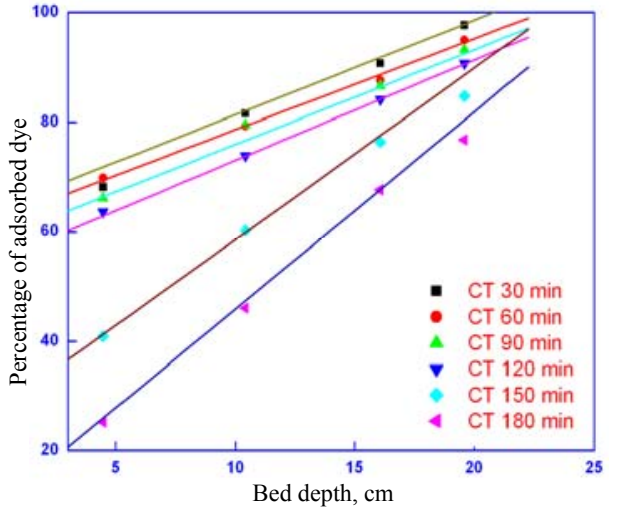

Figure 13. Effect of bed depth

\section{Kinetic aspects of dye adsorption}

In recent years, adsorption mechanism involving kinetics based models have been reported. Numerous kinetic models have described the reaction order of adsorption systems based on solution concentration. The efficiency of the process depends upon the kinetics and hence uptake or the contact time dependence of the concentration distribution of the solute in both the bulk solution and on solid adsorbent, besides the identification of rate determining step. Since, the solute is generally involved in the adsorption process a simple first order kinetics model was used to establish the rate of the reaction.

\section{Bhattacharya-Venkobhachar equation}

The Bhattacharya - Venkobhachar equation is

$$
\log [1-\mathrm{u}(\mathrm{t})]=-(\mathrm{k} / 2.303) \mathrm{t}
$$


Where $\mathrm{u}(\mathrm{t})=\left[\left(\mathrm{q}_{0}-\mathrm{q}_{\mathrm{t}}\right) /\left(\mathrm{q}_{\mathrm{t}}-\mathrm{q}_{\mathrm{e}}\right)\right], \mathrm{q}_{0}, \mathrm{q}_{\mathrm{e}}$ and $\mathrm{q}_{\mathrm{t}}$ are the concentrations of dyes at the initial time, equilibrium time and at time $\mathrm{t}$ in min and $\mathrm{k}$ is the first order rate constant for adsorption $\left(\mathrm{min}^{-1}\right)$. The Bhattacharya - Venkobhachar plots of $\log [1-\mathrm{u}(\mathrm{t})]$ vs. contact time ' $t$ ' are presented in the Figure 14.

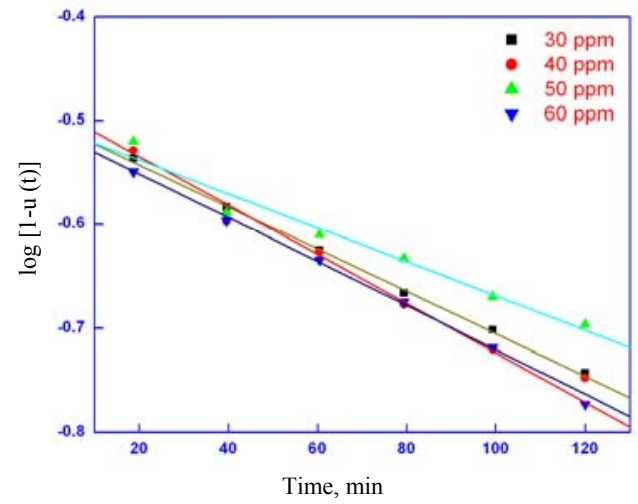

Figure 14. Bhattacharya-Venkobhachar plot

The straight line nature of these curves indicates that the sorption could be approximated to first order reversible kinetics. The rate constant $\mathrm{K}$ was calculated and it was ranged from $3.77810^{-3} \mathrm{~s}^{-1}$ to $5.43610^{-3} \mathrm{~s}^{-1}$.

\section{Lagergren's equation}

Lagergren's first order rate equation is the earliest known one describing the adsorption rate based on the adsorption capacity.

$$
\log \left(\mathrm{q}_{0}-\mathrm{q}_{\mathrm{t}}\right)=\log \mathrm{q}_{\mathrm{e}}-(\mathrm{k} / 2.303) \mathrm{t}
$$

Where, $q_{0}, q_{e}$ and $q_{t}$ are the amount of dye adsorbed at initial time, equilibrium time and time $\mathrm{t}$ respectively, $\mathrm{t}$ is time in min and $\mathrm{k}$ is the first order rate constant. In the present study, the plot of $\log \left(\mathrm{q}_{0}-\mathrm{q}_{\mathrm{t}}\right)$ vs. time is well fitted as a straight line (Figure 15) and reveals that the system obey first order kinetics. The regression values ' $r$ ' is in the range 0.9891 to 0.9978 . The correlation coefficient values ' $r$ ', are in the range 0.9810 to 0.9956 .

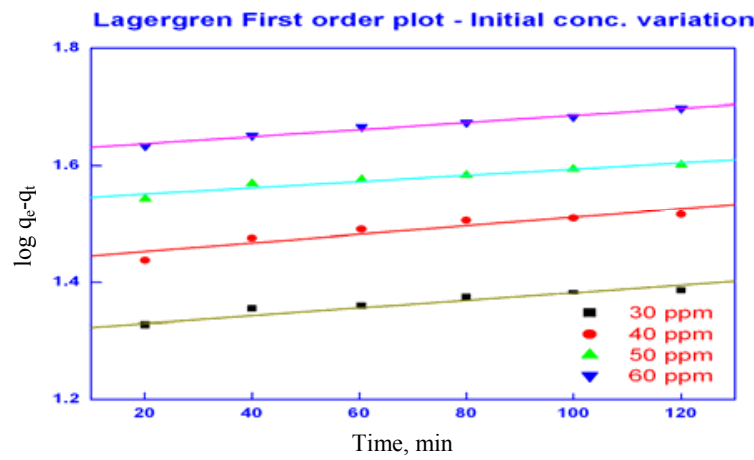

Figure 15. Lagergren's plot

\section{Intra-particle diffusion equation}

The variation in the extent of adsorption with time at different initial dye concentrations was processed for evaluating the role of diffusion in the adsorption system. Adsorption is a 
multi-step process involving transport of the solute molecules from the aqueous phase to the surface of the solid particulates followed by diffusion into the interior of the pores. The intra-particle diffusion rate equation ${ }^{18}$ is;

$$
\mathrm{q}_{\mathrm{t}}=\mathrm{k}_{\mathrm{i}} \mathrm{t}^{0.5}+\mathrm{c}
$$

Where $\mathrm{k}_{\mathrm{i}}$ is the intra-particle diffusion rate constant $\left(\mathrm{mg} \mathrm{g}^{-1} \min ^{0.5}\right), \mathrm{q}_{\mathrm{t}}$ is the amount of dye adsorbed in time $t$ and $\mathrm{c}$ is the intercept. The regression coefficients were found to be of 0.9148 to 0.9994 . The $k_{i}$ values were in the range of 0.680 to $4.552 \mathrm{mg} \mathrm{g}^{-1} \min ^{0.5}$. The linearity of the plots demonstrated that intra-particle diffusion played a significant role in the uptake of the dye by the activated carbons. This also confirms that adsorption of the dyes on the adsorbents was a multi-step process, involving adsorption on the external surface and diffusion into the interior. In all cases the lines were not passing through the origin. In the present work the absence of multi lines in the plots, indicated that the steps were indistinguishable from one another ${ }^{16}$.

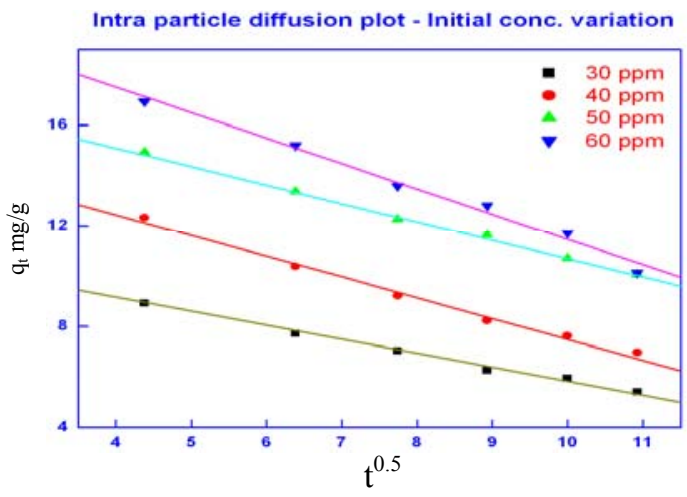

Figure 16. Intra-particle diffusion plot

In the present work the linear plots of $\mathrm{q}_{\mathrm{t}} v s$. $\mathrm{t}^{0.5}$ have intercepts ranges between 9.101 to $44.98 \mathrm{mg} \mathrm{g}^{-1}$, it may be concluded that surface adsorption and intra-particle diffusion were concurrently operating during the interaction of dye and the adsorbent. The process of adsorption of the dye follows a homogeneous mode i.e., the diffused dye particles may ooze out to the surface without locking. This supports the assumption of Langmuir that the intermolecular forces between the sorbate and sorbent would not be significant beyond the first sorbed layer and that a portion of the sorbate molecules adheres, while the reminder renounce into the liquid phase.

Natarajan Khalaf equation

Natarajan Khalaf equation is

$$
\log \left(\mathrm{q}_{0} / \mathrm{q}_{\mathrm{t}}\right)=(\mathrm{k} / 2.303) \mathrm{t}+\mathrm{c}
$$

Where $\mathrm{q}_{0}$ and $\mathrm{q}_{\mathrm{t}}$ were the dye concentrations at time zero and time $\mathrm{t}$ respectively and $\mathrm{k}$ is the rate constant. A plot of $\log \left(\mathrm{q}_{0} / \mathrm{q}_{\mathrm{t}}\right)$ vs. $\mathrm{t}$ (Figure 10, Figure 17) fits a linear curve. The ' $\mathrm{r}$ ' $\&$ ' $r$ ' values range from 0.9877 to $0.9989 \& 0.9905$ to 0.9967 respectively. It reveals that the systems are well fitted with this equation and follows a monolayer physisorption type.

\section{Elovich equation}

Elovich equation has been widely used in adsorption kinetics to describe chemisorption mechanism involving heterogeneous system. The adsorption data is also analyzed using the Elovich equation;

$$
\mathrm{dq}_{\mathrm{t}} / \mathrm{dt}=\alpha \mathrm{e}^{-\beta \mathrm{qt}}
$$


Where $\mathrm{q}_{\mathrm{t}}$ is the sorption capacity at time $\mathrm{t}\left(\mathrm{mg} \mathrm{g}^{-1}\right), \alpha$ is the initial adsorption rate constant $\left(\mathrm{mg} \mathrm{g}^{-1} \mathrm{~min}^{-1}\right)$ and $\beta$ is the desorption constant $\left(\mathrm{mg} \mathrm{g}^{-1} \mathrm{~min}^{-1}\right)$. Elovich plots (Figure 18) are not linear which reveals that the adsorption is not chemisorption. This is also in conformity with earlier study ${ }^{19}$.

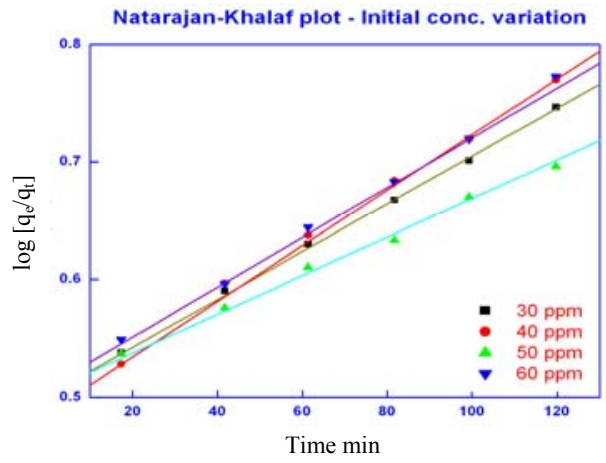

Figure 17. Natarajan Khalaf plot

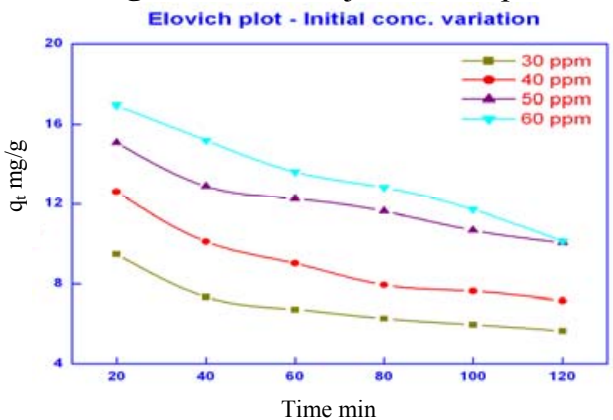

Figure 18. Elovich plot

\section{Modified Elovich equation}

The modified Elovich equation is

$$
\left(q_{0}-q_{t}\right)=(1 / \beta) \ln (\alpha / \beta)+(1 / \beta) \ln t
$$

Where $q_{0}$ and $q_{t}$ are the amount of dye adsorbed initially and at equilibrium respectively. The plot (Figure 19) gives a smooth, single curve without any notches denote that the systems, with fixed initial concentrations of the dye and carbon form a monolayer of physisorption.

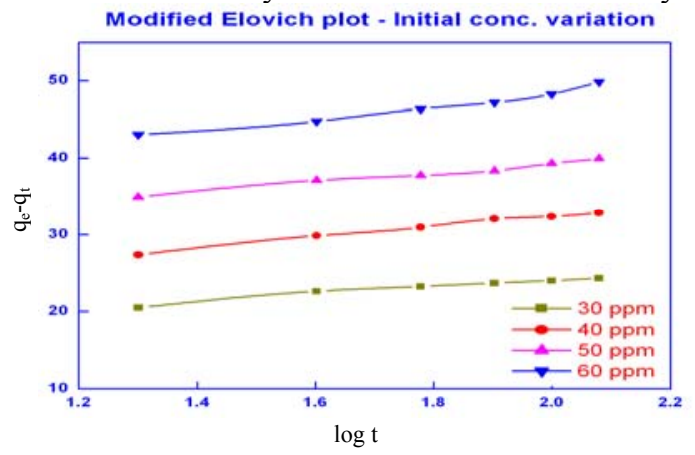

Figure 19. Modified Elovich plot 


\section{Pseudo second order equation}

The pseudo second order kinetic equation is

$$
\mathrm{dq}_{\mathrm{t}} / \mathrm{dt}=\mathrm{k}_{2}\left(\mathrm{q}_{0}-\mathrm{q}_{\mathrm{t}}\right)
$$

Where $\mathrm{q}_{0}$ and $\mathrm{q}_{\mathrm{t}}$ are the sorption capacity at initial and at time $\mathrm{t}\left(\mathrm{mg} \mathrm{g}^{-1}\right)$ respectively and $\mathrm{k}_{2}$ is the rate constant of the pseudo second order sorption $\left(\mathrm{mg} \mathrm{g}^{-1} \min ^{-1}\right)$.

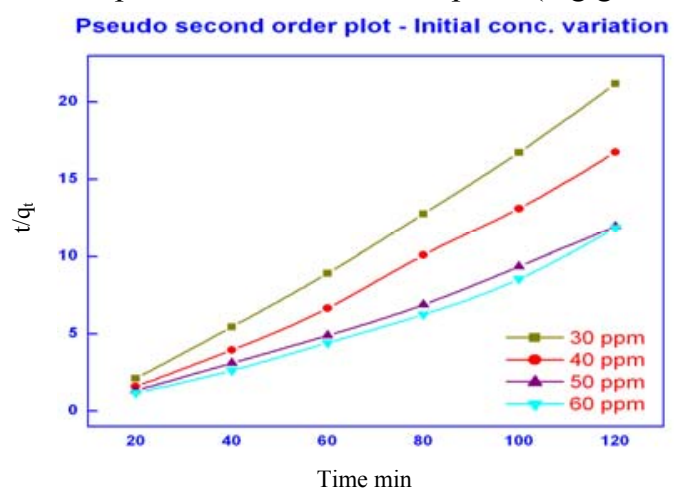

Figure 20. Pseudo second order equation

\section{Effect of contact time and initial dye concentration}

The experiments were carried out for the adsorption at various concentrations of dyes, 30 , 40, 50 and $60 \mathrm{ppm}$ with contact time 20 to $120 \mathrm{~min}$. Figure 7.8 to 7.14 reveal that percent adsorption decreased with increasing initial dye concentration, but the actual amount of dye adsorbed per unit mass of carbon increased with increase in dye concentration. It means that the adsorption is highly dependent on initial concentration of dye. It is because of the reason that at lower concentration, the ratio of initial number of dye molecules to the available surface area is low.

\section{Conclusion}

The results of this work can be summarized as follows:

i) Jatropha curcus L leaves powder carbon is a promising adsorbent for removal of the dye DY-12 from water. A small amount ( $1 \mathrm{~g} / \mathrm{L})$ of the adsorbent could almost completely decolorize an aqueous solution of DY-12 (40 mg/L) if agitated for $5 \mathrm{~h}$.

ii) The experimental data produced perfect fit with the Freundlich isotherm showing that the surface of the JCTC particles was heterogeneous.

iii) The data were in good agreement with the Langmuir isotherm.

iv) The volume of effluent that could be treated is found to be $262 \mathrm{~L} / \mathrm{g}$.

v) The adsorption of the dye on JCTC followed pseudo first order kinetics with the interactions largely over within the first hour.

vi) The SEM analysis and FT-IR spectrum clearly shows that the adsorption is by the physical forces and not by the chemical combinations.

\section{Acknowledgement}

The authors are grateful to the Chairman, Vice Chairman, Joint Management Trustee, Principal and the authorities of the Sri Subramanya College of Engineering and Technology, Palani and Manonmanium Sundaranar University for providing necessary facilities to complete this work. 


\section{References}

1. Mackay G and Andrew G S, Water Air Soil Pollut., 1980, 14(1), 3-11; DOI:10.1007/BF00291821

2. McKay G, Am Dyestuff Rep., 1979, 68, 29-34.

3. Lourento N D, Novais J M and Pinheiro H M, Biotechnol Lett., 2006, 28(10), 733-739; DOI:10.1007/s10529-006-9051-5

4. Lluís Núñez, José Antonio García-Hortal and Francesc Torrades, Dyes Pigm., 2007, 75, 647-652; DOI:10.1016/j.dyepig.2006.07.014

5. Yang, C L and McGarrahan J, J Haz Mater., 2005, 127(1-3), 40-47; DOI:10.1016/j.jhazmat.2005.05.050

6. O'Connell D, Birkinshaw C and O'Dwyer T F, Bioresource Technol., 2008, 99, 6709-6724; DOI:10.1016/j.biortech.2008.01.036

7. Ali Rıza Dinçer, Yalçın Güneş, Nusret Karakaya and Elçin Güneş, Bioresource Technol., 2007, 98, 834- 839; DOI:10.1016/j.biortech.2006.03.009

8. Walker G M and Weatherley L R, Water Res., 1997, 31(8), 2093-2101; DOI:10.1016/S0043-1354(97)00039-0

9. Walker G M and Weatherley L R, Environ Pollut., 1998, 99(1), 133-136; DOI:10.1016/S0269-7491(97)00166-8

10. Khattri S D and Singh M K, Water Air Soil Pollut., 2000, 120(3-4), 283-294; DOI:10.1023/A:1005207803041

11. Kannan N and Veemaraj T, EJEAFChem., 2010, 9, 1156-1167.

12. Gayathri U, Venkatraman B R and Arivoli S, J Chem Pharm Res., 2011, 3(1), 628-648.

13. Huang C P and Wirth P K, J Environ Engg ASCE., 1982, 108(6), 1280-1299.

14. Hall K R, Eagleton L C, Acrivos A and Vermeule T, Ind Eng Chem Fund., 1966, 5(2), 212-219; DOI:10.1021/i160018a011

15. Weber W J and Morris J C, J Sanit Eng Div Am Soc Civ Eng., 1963, 89, 31- 60.

16. Ho Y S, Water Res., 2003, 37(10), 2323-2330; DOI:10.1016/S0043-1354(03)00002-2

17. Ho Y S and McKay G, Chem Eng J., 1998, 70(2), 115-124; http://dx.doi.org/10.1016/S0923-0467(98)00076-1

18. Meshko V, Markovska V, Mincheva M and Rodrigues A E, Water Res., 2001, 35, 3357-3366; http://dx.doi.org/10.1016/S0043-1354(01)00056-2

19. Augustine A A, Orike B D and Edidiong A D. EJEAFChem., 2007, 6, 2221- 2234. 